\title{
Researching together: Reflections on ethical research in remote Aboriginal communities
}

\begin{tabular}{c|c} 
Tessa Benveniste & Lorraine King \\
CQUniversity & kungkayi@live.com \\
t.benveniste@cqu.edu.au & \\
\hline
\end{tabular}

Keywords: ethics, remote communities, Aboriginal research, ethical practice

\begin{abstract}
Ethical research with Aboriginal and Torres Strait Islander peoples is a complex and delicate space. It often juxtaposes Western views of ethical practice with Indigenous worldviews and values. The lead author's doctoral research project has focused on the expectations, experiences and outcomes of boarding school for remote Aboriginal students, families and communities. This paper presents a thematic analysis of the reflections of the authors on working together on this research as a non-Indigenous researcher and an Aboriginal Community Researcher. Strategies to implement what the authors and literature describe as ethical practice in remote Aboriginal communities are discussed. Implications for future research and lessons learned through this experience are identified.
\end{abstract}

\section{Introduction}

This paper focuses on the ethical implications of working on a research project with remote Aboriginal families and communities. In particular, it explores the key elements believed to have contributed to ethical practice in addressing the past, developing cultural and contextual knowledge and working together as non-Indigenous and Indigenous researchers. The term "Indigenous" will be used interchangeably with "Aboriginal and Torres Strait Islander peoples" throughout this paper, with no intent to disrespect the diversity and individual identities of the many different peoples and groups across Australia and overseas. Within Australia alone, for example, there are more than 300 distinct Aboriginal "countries" (Jackson-Barrett et al., 2015); however, where previous research has not identified the distinct group, or refers to Indigenous peoples across the world, we have used the term Indigenous. Whenever possible we refer more specifically to Australian Aboriginal and Torres Strait Islander peoples or their individual language or cultural groups.

One of the major tensions that occur when approaching research in Indigenous communities is the history of research in the field. As the literature highlights, past research has been a tool of colonisation, and has often been used largely to benefit the researcher and their institution rather than the communities themselves (Gower, 2012; Wilson, 2008). Since colonisation, research surrounding Aboriginal and Torres Strait Islander peoples and contexts has also been marred by practices that researched "on" rather than "with" communities, often excluding their voices or ways of doing and knowing (Martin, 2008; Smith, 1999). Such research has not always necessarily been ill-intended, often arising as a result of concern regarding reducing inequalities between Indigenous peoples and the (predominantly white) non-Indigenous population (Liamputtong, 2010). Yet, it is important to consider Indigenous 
knowledge in relation to academic research, which continues to colonise, appropriate and marginalise Indigenous knowledge traditions (Christie, 2006). Research most often evolves from funding bodies (government and non-government), universities, or research centres that are dominated by Anglo-Celtic cultural values (Gorman \& Toombs, 2009). Universities in particular subscribe to institutional practices of Western and scientific knowledge traditions (Nakata, 2007). An example of these Euro-Western knowledge traditions is that they largely focus on comparing and contrasting, whilst Indigenous knowledge systems tend to look for connection and the relationships between things (Hall, 2014). Translation of knowledge, such as through storytelling, also reflects oral traditions and an epistemological "way of doing things" for many Indigenous cultures (Jackson-Barrett, Price, Stomski, \& Walker, 2015). Finding a way to acknowledge and privilege these knowledges and traditions within a research framework is imperative to preventing the perpetuation of damaging research practices with Indigenous people and communities.

Reviewing the above history may cause a non-Indigenous researcher to take pause or reconsider researching with Indigenous peoples, with feelings of guilt or trepidation. However, while one should consider the space and its history very carefully, it is not necessarily useful to simply avoid the uncomfortable, as this leaves space for perpetuating the past. As Herring, Spangaro, Lauw, and McNamara (2013) suggest, "reading the work of Aboriginal writers, attending cultural events, responding to racism, and taking the initiative to engage with Aboriginal colleagues and acquaintances" may be a more productive way forward (p. 112). Furthermore, Indigenous peoples worldwide from Australia, Canada, New Zealand, and the United States (among others) are now pushing back against this history, moving forward and advocating for ownership, control and possession of research in their communities and on or with their peoples (Gower, 2012). As Hall (2014) explains, many Indigenous researchers and academics have also been speaking back to the Academy, rethinking research processes through an Indigenous lens, and strongly acknowledging the consequences of past research practices. Furthermore, while academic research questions traditionally emerge from specific disciplines (Wilson, 2008), recent research explores questions that arise from needs perceived and identified by governing bodies, or from the community themselves (Christie, 2006). Indigenous Australian academics have also proposed decolonising research methodologies such as Indigenist research (research conducted by Indigenous people) (Rigney, 1999), detailing what they believe to be appropriate methods of data collection in Indigenous contexts (Fredericks et al., 2011; Nakata, 2007), and advocating privileging Indigenous peoples, narratives and epistemologies in research (Jackson-Barrett et al., 2015; Smith, 1999).

\section{Methods}

\section{Positioning as researchers}

The authors of this paper acknowledge that researchers have multiple and varied positions, roles, and identities that are intricately and inextricably embedded in the process and outcomes of their research (Ladson-Billings \& Donnor, 2005). Therefore we will briefly identify our positioning as researchers. Tessa is a doctoral research student in the field of Social Psychology, and is of European-Scottish descent. She grew up and lives in Adelaide, on Kaurna country. Lorraine is a Senior Aboriginal Community Researcher, born and raised in Papunya community 240 kilometres north-west of Alice Springs. She identifies as a PintupiLuritja Warlpiri woman, and was raised by her grandmother, spending most of her childhood between Papunya and her grandfather's homeland (Central Mount Wedge), on Warlpiri country. She is a qualified interpreter in Pitjantjatjara, Luritja-Pintupi, and Warlpiri languages. Both authors view education and sharing of knowledge as a positive space that will allow Aboriginal communities and non-Aboriginal peoples to work together with common goals. 


\section{The broader research project}

The broad aims of the 4-year research project were to explore the expectations, experiences and outcomes of boarding school for remote Aboriginal students, families and communities. In order to investigate these aims, the project employed a qualitative research design, from a Grounded Theory perspective. The flexibility and fluidity of qualitative research provides scope for understanding the meanings, interpretations and subjective experiences of individuals (Liamputtong, 2010). It is deemed a particularly useful approach to allow space for the voices of those who are often silenced, othered or marginalised to be heard, and to present counternarratives (as described in Critical Race Theory) (Ladson-Billings, 1999; Milner, 2007). The research also used a case study approach of a residential program in South Australia, which is accessed mainly by Anangu (people) from communities across the Anangu Pitjantjatjara Yankunytjatjara (APY) lands. Findings are discussed in several prior and upcoming publications (Benveniste, Dawson, Guenther, Rainbird, \& King, 2016; Benveniste, Dawson, \& Rainbird, 2015; Benveniste, Guenther, Rainbird, \& Dawson, 2016).

\section{The current paper}

The current paper explores the reflections of the two authors on working together on the lead author's doctoral research project. Thematic analysis on the oral and written reflections was conducted to identify the key themes and ethical considerations that arose in the project. These themes are integrated with the literature on ethical practices with Indigenous peoples in an attempt to provide a useful analysis of our individual experiences and how they relate and may be useful to other researchers working with and in remote Aboriginal communities across Australia.

\section{Results}

Looking back as the project drew to a close, we (Tessa and Lorraine) reflected on what ethical practice meant to us, and how we approached ethical conduct in the communities that were part of the study. Tessa's reflections were in written form, and Lorraine provided oral reflections, which were transcribed and integrated with Tessa's reflections below. Thematic analysis of both of our reflections identified five overarching themes; (1) Addressing the past, (2) Translating formal ethical requirements into practice, (3) Developing cultural and contextual knowledge, (4) Approaching communities, and (5) Working together.

\section{Addressing the past}

There is consensus among Indigenous and non-Indigenous scholars alike that Indigenous peoples have become the "most researched people in the world" (Gorman \& Toombs, 2009; Jackson-Barrett et al., 2015; Martin \& Mirraboopa, 2003; Wilson, 2008). Yet, despite countless research papers, academic accolades, interventions, and policy decisions, few tangible benefits of research appear to have been seen in the lives of Aboriginal and Torres Strait Islander peoples (Hall, 2014). Over-research in these communities has arguably caused a great deal of mistrust in the research process, and often brings animosity and resistance from many Aboriginal people (Martin, 2008). Fear of exploitation and misrepresentation are also effects of research that have resulted in mistreatment and marginalization from structures and governance or misguided policies (Christie, 2006). The not-so-distant history of research without permission, consultation or involvement of Aboriginal people also plays a large role in this fear (Martin \& Mirraboopa, 2003). 
As a post-graduate researcher, for me (Tessa), facing the history of research in indigenous contexts has been one of the most difficult parts of the research process. Other than following the guidelines set by the formal ethics committees, I was challenged with the question of how, in a practical sense, can research be turned around and used positively in Aboriginal and Torres Strait Island communities? Having come into my studies with the view that research may provide a tool for reflection, a vehicle for communities and families to be heard, a platform for evidence-based practice, and a possibility for new approaches to the boarding space, it has been an ongoing challenge to try to ensure past practice and approaches to research are not perpetuated (knowingly or not) in my own work. While in theory, non-Indigenous researchers may value diversity and acknowledge the importance of social, cultural, economic, geographical and historical contexts, in practice we are still required to navigate "unfamiliar experiences and settings, alternate worldviews, unarticulated assumptions, deeply held values, and the strong but often invisible forces of power and privilege" (Bond \& Harrell, 2006, p. 157). While it can be intimidating to read the literature on ethics and research with Indigenous communities in Australia and around the world, it is our belief (as a non-Aboriginal and an Aboriginal researcher working together), that this should not cause non-Indigenous researchers to turn away from the field, but rather should inspire us to work harder to develop new methods and approaches to ensure research is used ethically and with every attempt to provide positive outcomes for communities.

When I (Lorraine) first got into research, I thought it was a fun thing to do. Now, research is different to me; it is about helping Aboriginal people, whether it is in education, health, housing - research is important for those things. I think someone like me having cultural understanding and language helps people in communities to trust research again, because they can see that there are people who do have good intentions to make them count so they can get support. For example, if there isn't education like a secondary school in community, then they can get that done. If they have a bit of education then they can have a better understanding of those things, in order to advocate for what they want. I owe it to my grandmother because I have the language and the culture for free, I'm forever indebted to her for that, and by getting me to have an education she has given me the ability to be able to work with people like you (nonAboriginal people) and explain my Aboriginal culture.

When research is dominated or controlled by non-Indigenous researchers, inappropriate research methodologies, which have been invasive and ignorant of the rights of Indigenous people, have abounded (Fredericks et al., 2011; Gower, 2012). Further, when such research is undertaken based on the decision of the researcher or their institution, rather than based on community-driven request or need, it can be disconnected from or irrelevant to the community, excluding them and their agency from the research process. As a consequence, the ownership, interpretation and dissemination of findings are also often controlled by academics, stored in universities and not shared with Indigenous communities (Gower, 2012). Communities are quite used to seeing researchers arrive, do what they feel they need to, and then leave (Wilson, 2008). Thus, it is understandable that research is not always embraced or viewed positively by many Aboriginal and Torres Strait Island communities.

I (Lorraine) think researchers should also be extremely clear about their intentions with the research. Being clear about what you are doing, why you are there to do the research is very important. With the past histories, research can still be a scary thing in Aboriginal communities. What happened with the Northern Territory Intervention (see Calma, 2007) is still very much in people's minds. Research in the past has been used to "show" things, or been used to justify policies such as the Intervention. So while communities may be willing to give to you and the research, they are still hesitant to say exactly what they want. Milner (2007) echoes this concern, warning of the dangers that can emerge from research should misinterpretations, misinformation or misrepresentation of individuals, communities and systems occur. 


\section{Translating formal ethical requirements into practice}

All research involving humans or animals requires approval from research ethics committees prior to the commencement of research activity. Additional to the guidelines provided by the National Health and Medical Research Council (NHMRC), individual university ethics committees assess and monitor proposed research activities. In response to past practices, and as the research community move toward working with Indigenous knowledges and worldviews, ethics committees have worked to create guidelines for research with Aboriginal and Torres Strait Island communities. Specific values that the NHMRC identify in particular regarding research with Aboriginal and Torres Strait Islander people include spirit and integrity, reciprocity, respect, equality, survival and protection, and responsibility (NHMRC, 2003). Increasingly, Aboriginal and Torres Strait Islander people have also become involved in the ethics process (Gower, 2012), establishing local and tailored ethics committees such as Aboriginal Health Research Ethics Committee (AHREC) and the Central Australian Human Research Ethics Committee (CAHREC). As Christie (2006) notes, however, addressing these ethics committees and meeting these requirements can be considered a "necessary evil" in research. Timelines, addressing multiple committees, and working with educational ethics requirements was at times overwhelming, particularly at the early stages of a research degree. However, as I (Tessa) conducted the research and addressed the questions and guidelines provided by these committees, I found a much better appreciation of how "necessary" they are. For example, the questions that the ethics committee posed forced me to dig deeper into my consideration of methodology and the processes which I would follow to mitigate any unforeseen harm to participants.

For me (Lorraine), I am always seeing two types of ethics, Aboriginal ethics, and non-Aboriginal (Western) ethics. Aboriginal ethics involves approaching communities appropriately, making sure I talk to the right people, being clear, understanding that every community is different to your own but still respecting them. Regardless of your work responsibilities, there are other respects you need to show as an Aboriginal person. It is important to let people know who I am and what my background is, to introduce myself properly. Sometimes I have conducted research in communities where I knew people previously (I had worked in those communities before), but when I do research in new communities it is even more important to let them know where I come from and that I speak their local language. When not working on your own country, as an Indigenous researcher you need to connect with any Aboriginal organisations, Land or Sea Councils to establish who the elders are in the country you intend to work. These elders will then guide you in appropriate protocols, approaches and methodologies in which to conduct the research. I also make sure to explain carefully what the researcher wants me to do, and what the Western ethical codes are, like confidentiality, integrity, and respect. I talk to people with respect, and to me speaking language itself is a sign of respect.

While the above institutional procedures for ethical approval are required, and a necessary part of the research process, they could be considered insufficient in guiding ethical research practice in physically remote contexts (Osborne, 2016a). One needs to consider what different worldviews or knowledge systems see as ethical, and how to meet what may be competing requirements. Therefore, as Hall (2014) explains, ethics is not something to be approached on the surface, but something to consider in the way you operate as a researcher, how you value and respect the relationships built through your research, and how to honour these upon completion of the formal research process. Through personal observations over the years of colleagues and other non-Indigenous researchers in this space, it seems there is a common theme of researchers entering the space after years of engagement and experience working in or with remote communities. Not having previously worked in remote communities, I (Tessa) had no prior experience in this field, nor did I have any established relationships. Despite valuing them greatly, it therefore seemed an uphill battle to develop genuine relationships and research that was based on what the community wanted. 


\section{Developing cultural and contextual knowledge}

Cultural competence is defined by Universities Australia, as cited in Gower (2012, p. 10) as:

The awareness, knowledge, understanding and sensitivity to other cultures combined with a proficiency to interact appropriately with people from those cultures in a way that is congruent with the behaviour and expectations that members of a distinctive culture recognise as appropriate among themselves.

Cultural sensitivity is considered one part of cultural competence. Demonstrating cultural sensitivity (an important aspect of engaging in cross-cultural research) is about gaining an understanding of another person's culture, beliefs and values and applying these understandings in practical situations (Liamputtong, 2010). The ability to gain and improve cultural sensitivity is made difficult due to the pragmatic considerations of working in very remote Australian communities, particularly the cost of travelling such vast distances to meet with participants (Osborne, 2016b). Much of the process and approach to ethical practice in this research project occurred from Adelaide, rather than being able to spend extensive time in the APY lands. What is often missed in the deeper discussions of ethical practice in remote communities is the practical steps that researchers must take before they can truly understand the concept of ethics. For me (Tessa), living in Adelaide, one of the biggest challenges was to develop relationships, cultural and contextual knowledge of the families and communities in the APY lands. This process occurred well before conducting the semi-structured and narrative interviews across Adelaide and the APY lands communities that formed the data for my research. To gain an understanding of the practical context from afar, I first spent time volunteering at the boarding residence in Adelaide over a period of eighteen months. This time allowed me to familiarise myself with the boarding residence, and to build relationships with staff, students, and some families. It was also my way of following the principle of Ngapartji ngapartji - a Pitjantjatjara term that encompasses the practice of reciprocity and giving back. Concurrently, I was also fortunate enough to attend a Pitjantjatjara language summer school, run by the University of South Australia. During this two-week course, I was not only introduced to the Pitjantjatjara language, but also to several Anangu tutors, who provided guidance on culture and community life. Although this is a language course, rather than specifically a "cultural competency" course, I consider the experience to have been a part of my cultural competence training. Through the initial two-week course, followed by a year of weekly Pitjantjatjara language classes, I was also able to make contact and develop a network with others who had previously or were currently living and working in the communities where I would be carrying out research. Over this time, the research directions became clearer, through conversations with community members, families, past boarding students, and current boarding staff, leading to refining of the broad research questions and allowing me to gain confirmation of their desire for the research to be conducted.

Due to the practical realities of working in very remote Australia, and with limited research resources, finding these ways to connect with community members and learn about Anangu culture from afar was invaluable. It is extremely fortunate that Pitjantjatjara is still a strong language and that Anangu are willing and able to share their language with others - particularly with so many Aboriginal languages having been lost through colonisation. For those who don't have the opportunity to learn local language, I would suggest that other strategies could be found, relevant to each context, (for example, speaking with local elders or community members in the region within which you research or attending and celebrating local events) to gain an understanding of what is important to the communities you work with, their values, their expectations of research, and their expectations of your interactions. 


\section{Approaching communities}

Recent discussions have argued against the deficit discourse that often surrounds narratives around Aboriginal and Torres Strait Islander communities. Much of the deficit narrative stems from government priorities around Closing the Gap - which refers to the reported gaps in health and education measures between Aboriginal and Torres Strait Islander peoples and other Australians (Australian Government, 2017). Part of the issue with this rhetoric is that it sets Aboriginal and Torres Strait Islanders up as different or "other" in comparison to the rest of the Australian population, or positions them as a "problem" to be fixed. Research has been perpetuating "othering" since colonisation - setting Euro-Western knowledge systems as the norm, or what should be aspired to, and Indigenous knowledge systems as inferior (Wilson, 2008).

I (Lorraine) think that when they are approaching research in Aboriginal communities, researchers should consider a number of things. First, acknowledging that there are cultural differences that may exist. Being open-minded about different cultures, and understanding that language, cultural beliefs, and the place that they live in - their community - is their world. Having said that, you should still approach people as normal - don't see them as "different" or a "problem" or a "subject", they are still just people.

Even with a team that included an Indigenous academic, Jackson-Barrett et al. (2015) noted that it can be easy to underestimate the complex navigation between Western research and Indigenous community protocols. However, as Milner (2007) states, actively engaged, thoughtful researchers who are upfront about issues or tensions that can surface around race and culture should not necessarily be excluded from conducting research outside of their own racial or cultural community.

When I (Lorraine) am working with communities I might not know or be familiar with their protocols, being respectful when approaching communities means making sure that what you are doing is culturally appropriate, so you aren't breaking rules. Some researchers just go in there and do it - they might have an Aboriginal person with them, but that person may not know about culture, how things work or the protocols in that community. You first need to know who the right people are to approach, and go to them to break the ice, otherwise it is upsetting if they don't know who you are. Sending notices to schools, health clinics, or shops isn't enough either, you need to visit the community without the research first (so without thinking about or talking about the research), and see how people are with you. If you can, going with someone else who is already researching in the community to see how they are working and conducting their research can help you get an introduction and start to build trust. Approaching communities with respect can be done in two ways: (1) contacting and working through community councils or chairpersons, or (2) working with another Indigenous person who is familiar with the community rules and protocols who can act as a cultural broker. Visiting communities at least twice in one week also allows people to become aware that you are there, and have some time to decide if they would like to participate.

\section{Working together}

When I (Tessa) commenced data collection, despite having gained some language skills, and having developed a small network of relationships with APY community members (non-Anangu and Anangu), something was still missing. I was still not confident that this alone would equip me to navigate the local and contextual ethical and practical requirements necessary for this research. I was introduced to Lorraine when she was working with a colleague in one of the communities involved with the research. I observed the enormous value in her language 
skills, cultural knowledge, and experience working with communities, and it became clear that working with Lorraine in her capacity as an interpreter and an Aboriginal Community Researcher could greatly enhance the quality and ethical management of this project. It was not a relationship that was established in order to have a "token Indigenous researcher" or to attract funding as Christie (2006) suggests is the case in some research, but a genuine attempt to support participants, the research, and my approach as a researcher in a positive way. Working together allowed me to better understand the cultural considerations I needed to take into account, helped facilitate relationships with participants, and made it easier to develop trust and understanding about the research aims.

Trusting the person you are working with (like me, Lorraine) is important. Clear communication with them, valuing them as a part of the team, and acknowledging their role in your research makes a huge difference. I have always felt that I've been included as a part of the research Tessa has done, not just by her including me in presentations, but maintaining an ongoing relationship, asking for my advice, and keeping in touch about where it is up to. It isn't always possible to include your Aboriginal Community Researcher in presenting or writing, but whenever possible you should. Keeping in mind that what you want to do might have to change when you get to the community, a willingness to learn from and listening carefully to the Aboriginal Community Researcher and allowing for flexibility will improve your chances of achieving a better overall outcome. This trust flows on to being able to maintain an open mind as to how the research evolves. I (Lorraine) have noticed that respectful researchers often have particular personal characteristics. For example, open mindedness, being able to listen, and not being judgemental is really important. Being flexible in your approach to the research and how it should be done helps a lot, but you have to be able to trust that you will still get the result; it just may take a different approach.

The research itself was also improved by working together, with Lorraine guiding me (Tessa) in making the interview questions accessible and easier to interpret for participants. At no stage did this change the meaning of what we were asking, but it allowed questions to be relatable, understood, and more closely aligned to what was being interpreted in Pitjantjatjara. By having Lorraine interpret many of the interviews, participants who were more hesitant or less confident with speaking English (for some, English is their second, third, or fourth language) were able to express themselves and tell their stories in their own language. This allowed the conversation to open up more, and also allowed the participants' own narrative to be heard.

When you are working with an Aboriginal person who is interpreting (like me, Lorraine), or an Aboriginal Community Researcher, there are some tricks to being able to work smoothly together. With an interpreter, it is important to find a rhythm with each other and to have signals or a system to indicate when to pause for interpretation. For example, certain phrases or sentences will take longer when spoken in Pitjantjatjara than in English, so you need to have a briefing to work out the timing before you conduct interviews or engage with community members. Secondly, being really clear about the role the interpreter or researcher is playing; are they interpreting only, or are they conducting the research? Be extremely clear about what you would like them to do, what you want to do with the research, what outcomes you are looking for, and then talk together to work out how best to deliver that.

In addition to enhancing my experience and knowledge of respectful behaviour in Anangu culture, working with Lorraine also gave me (Tessa) strength and confidence as a researcher. This was particularly important when visiting their country, homes and communities in the APY lands, thus Lorraine's encouragement, teaching and guidance was a huge support. Furthermore, her local knowledge of the terrain and logistical considerations such as travel on roads in poor weather, or finding accommodation within the communities, allowed the 
research to run more smoothly. Knowing when and where cultural events were occurring, such as funerals or men's ceremonies (which can make certain roads impassable) also prevented us from inappropriately entering communities or areas where we would be imposing upon or at risk of violating cultural protocols. Jackson-Barrett and colleagues (2015) suggest that negotiating appropriate timelines, and remaining aware that communities are not static entities (other situations may arise, taking priority over your research agenda), and being as flexible as possible can help make the research goals and community needs be prioritised accordingly. As Osborne (2016b, p. 70) explains,

Other cultural events and factors such as funerals, high levels of mobility and reciprocal obligations to family mean that a researcher's time schedule may not be suitable, even if things have been pre-arranged and confirmed prior to making the trip to the community. Flexibility in this regard is crucial.

I (Tessa) think what helped Lorraine and I work particularly well together was a joint willingness to learn, feeling that we both had ownership over the process, and patience with the research.

I (Lorraine) am still learning as a researcher, but I don't think I would have done anything differently. You never really know what will happen in communities, they can surprise you, so I never go in with an expectation of "this is what we will get" or "we won't be able to get this". Patience is something I definitely take with me. Being an Aboriginal Community Researcher has made me look at Aboriginal culture differently as well. By doing work and research in those communities, me working with non-Aboriginal researchers, it has added value in the research itself, because it's not only your research, it is ours, and being a part of a research project, as well, I'm proud of that, the research that l've done with you (Tessa), you've never said it is "your" research, even though you have done a lot of it, I've never felt like I wasn't a part of it.

\section{Summary and future directions}

The negative ramifications of past practices of research in Aboriginal, Torres Strait Island, and Indigenous communities across the world, are widespread. However, contemporary researchers can move forward by developing research that is cognisant of the past, respects Indigenous knowledges and worldviews, and meets the ethical requirements not only of institutions but of the communities involved in their research. While the NHMRC and Aboriginal ethics committees outline key considerations and requirements for ethical practice in remote communities, stories of how to implement these in practice are scarce. This paper contributes to the discussions of ethical practice (forming this special issue) by presenting the reflections of two researchers who worked together on the lead author's doctoral research project on the role of boarding schools for remote Aboriginal students, families and communities.

Different approaches for different stages of the research were adopted in order to meet what I (Tessa) believed to be ethical practice. Prior to data collection, challenges were presented as to how to gain cultural awareness and build relationships and understanding of the community contexts, when these contexts were more than 1500 kilometres from my research base. To mitigate this challenge I found that attending language classes and volunteering at the boarding residence for an extended period of time built these competencies and developed a network of relationships. When I commenced data collection, however, working with Lorraine as an interpreter and a cultural advisor improved my ability to connect with participants, and allowed me to understand the practical and ethical requirements of working within communities.

Lorraine provided her perspective on ethics as an Aboriginal Community Researcher, suggesting that ethical practice in communities involves approaching the right councils or chairpersons 
before conducting the research, and working with someone who is from the community or knows the appropriate cultural protocols and can act as a cultural broker. She also noted that respecting the person working with you as an integral part of the team is necessary, as well as finding ways to include them at various stages such as when reporting findings at conferences (not just when you are in communities).

In summary, despite limitations as an outsider living at great distance from and with no prior experience working with Anangu communities, efforts were made to counteract these challenges. Others are encouraged to do so, as appropriate to their context. Challenges still exist; however, this paper provides a story of working together and is one example of a contemporary approach to research with remote communities. By no means is it a perfect approach, nor does it consider all aspects of what it means to conduct ethical research. Therefore, as researchers, we need to continue these discussions and be open about how to keep improving our practice and use research to genuinely benefit the communities with whom we work. As my doctoral research is drawing to a close, one of my major focuses has shifted to reporting back to the community on research findings. It is of course important to establish a reporting process with communities prior and during the research, and to make this contextual and relate to the community and their needs, but it is rarely clear how other researchers have achieved this. Future research could therefore identify examples of how this has been done. Furthermore, workshops, symposiums (such as the Knowledge Intersections symposium) and spaces to share ideas and support each other regarding ethical practice in remote research would be beneficial for experienced and inexperienced researchers alike. A national register for Aboriginal Community Researchers (similar to the National Accreditation Authority for Translators and Interpreters), training of more Aboriginal Community Researchers, and similar spaces for support and sharing of experiences and resources are also recommendations for the future. 


\section{References}

Australian Government. (2017). Closing the Gap: Prime Minister's Report. Retrieved from https://www. pmc.gov.au/sites/default/files/publications/ctg-report-2017.pdf

Benveniste, T., Dawson, D., Guenther, J., Rainbird, S., \& King, L. (2016). Parent perspectives on boarding: Insights from remote Aboriginal families. Paper presented at the Australian Association for Research in Education, Melbourne.

Benveniste, T., Dawson, D., \& Rainbird, S. (2015). The role of the residence: Exploring the goals of an Aboriginal residential program in contributing to the education and development of remote students. The Australian Journal of Indigenous Education, 44(2), 163-172. doi: 10.1017/ jie.2015.19

Benveniste, T., Guenther, J., Rainbird, S., \& Dawson, D. (2016). Deciphering distance: Exploring how Indigenous boarding schools facilitate and maintain relationships with remote families and communities Paper presented at the Australian Association for Research in Education, Fremantle, WA.

Bond, M. A., \& Harrell, S. P. (2006). Diversity challenges in community research and action: The story of a special issue of AJCP. American Journal of Community Psychology, 37(3-4), 247-255. doi:10.1007/s10464-006-9013-z

Calma, T. (2007). The Northern Territory "Emergency Response" Intervention - A human rights analysis. Social Justice Report. Retrieved 17 November 2017, from http://www.humanrights.gov.au/publications/ social-justice-report-2007-chapter-3-northern-territory-emergency-response-intervention

Christie, M. (2006). Transdisciplinary research and Aboriginal knowledge. Australian Journal of Indigenous Education, 35, 78-89.

Fredericks, B., Adams, K., Finlay, S., Fletcher, G., Andy, S., Briggs, L., Briggs, L., Hall, R. (2011). Engaging the practice of Indigenous yarning in action research. ALAR: Action Learning and Action Research Journal, 17(2), 7-19

Gorman, D., \& Toombs, M. (2009). Matching research methodology to Australian Indigenous culture. Aboriginal and Islander Health Worker Journal, 33(3), 4-7.

Gower, G. (2012). Ethical research in Indigenous Australian contexts and its practical implementation. Paper presented at the Innovative research in a changing and challenging world, Phuket, Thailand.

Hall, L. (2014). "With" not "about" - emerging paradigms for research in cross-cultural space. International Journal of Research \& Method in Education. doi: 10.1080/ 1743727X.2014.909401

Herring, S., Spangaro, J., Lauw, M., \& McNamara, L. (2013). The intersection of trauma, racism, and cultural competence in effective work with Aboriginal people: Waiting for trust. Australian Social Work, 66(1), 104-117. doi: 10.1080/0312407X.2012.697566

Jackson-Barrett, E., Price, A., Stomski, N., \& Walker, B. F. (2015). Grounded in country: Perspectives on working within, alongside and for Aboriginal communities. Issues in Educational Research, 25(1), $36-49$.

Ladson-Billings, G. (1999). Just what Is critical race theory, and what's it doing in a nice field like education? International Journal of Qualitative Studies in Education, 11(1), 7-24 .

Ladson-Billings, G., \& Donnor, J. (2005). The moral activist role of critical race theory scholarship. In N. K. Denzin \& Y. S. Lincoln (Eds.), The Sage handbook of qualitative research (Vol. 3, pp. 279-301). Thousand Oaks, CA: Sage. 
Liamputtong, P. (2010). Cross-cultural research and qualitative inquiry. Turkish Online Journal of Qualitative Inquiry, 1(1), 16-29.

Martin, K. (2008). Please knock before you enter: Aboriginal regulation of outsiders and the implications for researchers. Teneriffe, QLD: Post Pressed.

Martin, K., \& Mirraboopa, B. (2003). Ways of knowing, being and doing: A theoretical framework and methods for indigenous and indigenist research. Journal of Australian Studies, 27(76), 203-214. doi: $10.1080 / 14443050309387838$

Milner, H. R. (2007). Race, culture, and researcher positionality: Working through dangers seen, unseen, and unforeseen. Educational Researcher, 36(7), 388-400. doi: 10.3102/0013189x07309471

Nakata, M. (2007). The cultural interface. Australian Journal of Indigenous Education, 36, 7-14.

National Health and Medical Research Council (NHMRC). (2003). Values and Ethics: Guidelines for ethical conduct in Aboriginal and Torres Strait Islander health research. Canberra, ACT: Commonwealth of Australia. Retrieved 30 May 2018, from https://www.nhmrc.gov.au/ guidelines-publications/e52

Osborne, S. (2016a). Cultural capacity and development: The case for flexible, interdisciplinary research in remote Aboriginal and Torres Strait Island communities. Learning Communities, 19 (Special Issue: Synthesis and Integration), 46-63.

Osborne, S. (2016b). Staging standpoint dialogue in tristate education: Privileging Anangu voices. (Unpublished doctoral dissertation), Victoria University, Melbourne.

Rigney, L. I. (1999). Internationalisation of an Indigenous anti-colonial cultural critique of research methodologies: A guide to indigenist research methodology and its principles. Journal for Native American Studies, 14(2), 109-121.

Smith, L. T. (1999). Decolonising methodologies: Research and Indigenous peoples. London: Zed Books.

Wilson, S. (2008). Research is ceremony: Indigenous research methods. Black Point, NS: Fernwood. 